\title{
Patterns of European youngsters' daily use of media
}

\author{
Liliana Pacheco*, Marisa Torres da Silva**, Maria José Brites***, Sara Henriques****, \\ Manuel José Damásio***** \\ * Centre for Research and Studies in Sociology,University Institute of Lisbon CIES- IUL \\ ** Faculdade de Ciências Sociais e Humanas (FCSH), NOVA University of Lisbon \\ *** Universidade Lusófona do Porto e Centro de Estudos de Comunicação e Sociedade \\ $* * * *$ Universidade Lusófona/CICANT \\ $* * * * *$ Universidade Lusófona/CICANT
}

\begin{abstract}
The mediatisation of young people daily lives constitutes a significant subject due to the expressive use of media in their daily routines. In this article, we resort to a representative sample of 3609 online respondents aged between 14 and 30 years old from nine European countries (Belgium, Croatia, Denmark, Germany, Hungary, Israel, Italy, Poland and Portugal), in order to perceive the impact new (and "old") media have in these youngsters daily media consumption activities. The results of this online survey show complementary uses between networked and traditional media, but also highlight a gradual substitution of "old" by "new" networked individualized media when leisure and newsrelated activities are at stake.

Keywords: young e-audiences, online media, networked media, traditional media, mediatisation, media usage.
\end{abstract}

\section{Introduction}

This article focuses on the daily use of media by European e-audiences, from adolescence to young adulthood. Europe-the European Union and the rest of the region-represents a living laboratory of communication and culture. Growing out of a European Cooperation in Science and Technology (COST) Action involving more than 300 scholars from 33 countries (http://www.cost-transforming-audiences.eu), the nine-country study examined changing patterns of media use in Belgium, Croatia, Denmark, Germany, Hungary, Israel, Italy, Poland, and Portugal. Often thought of as one cultural unit, Europe, in fact, comprises a variety of political and economic systems and a similarly differentiated set of media systems (Hallin \& Mancini, 2004). Media users, in their turn, are local cultural agents who participate in, and contribute to, the ongoing structuration of their societies (Giddens, 1984). Media afford essential discursive resources of social action, that the data hereby presented and discussed grasps.

Data collection was conducted as an online survey (computer-assisted web interviewing, or CAWI), using the Ipsos commercial respondent panels in five of the nine countries (in Belgium, Croatia, Hungary, and Israel, identical procedures of data collection were undertaken using other panels). This process was completed during February 2013, with two exceptions: In Italy and Portugal, data collection was conducted during April 2013 because the planned survey dates coincided with key national events that received wide media coverage and which could thus be expected to skew media use patterns during that period. Data analysis and interpretation was conducted between 2014 and 2015.

The nine country samples were designed to be representative of the age distribution of the segment of the population that had access to the Internet in each country, for people aged 14 to 75.1 For the 
particular case of the analysis conducted in this paper, a partial sub-sample of 9 online respondents aged between 14 and 30 years, was considered. In addition, the national samples were balanced according to gender and across geographical regions in order to represent responses from both rural and urban areas. Because national statistics about the demographic composition of the online population vary considerably across the nine countries, both in terms of availability and quality and in terms of the demographic categories used, the study did not have a further basis of balancing across all national samples.

One single instrument was designed, translated and adapted to all countries and relevance assured via pre-testing in all countries. Sociocultural differences, inevitably, influenced the wording of questions, specifically regarding education and income, for which established national categories vary substantially. For income, respondents were informed of the median national income, and were next asked if their personal income level was (substantially) above or below this number. Since income levels differ markedly across the nine countries in the study, devising a meaningful set of intervals that would cover all countries was deemed unfeasible. A related but different problem had to do with educational levels: National educational systems in Europe differ substantially with regard to the classification of types and levels of schooling. Again, rather than attempting to devise a unified typology, respondents were asked about the number of years of education they had completed beyond mandatory elementary school. Upon completion of data collection, the educational data were recoded into an approximated International Standard Classification of Education (ISCED) classification (UNESCO, 2013).

Beyond recoding of the material, the national survey data were combined into a unified data set. During this process, the individual variables of all data sets were tested for consistency of structure, and variable names were homogenized in English to facilitate comparative and collaborative analyses. The final data set consists of 10,742 cases, with 1,200 to 1,216 cases from each of the nine countries, with the exception of the Belgian data set, which contains 1,100 cases.

The COST Action project approached the contemporary media environment as a cultural forum (Jensen \& Helles, 2011; Newcomb \& Hirsch, 1983), in which classic human and social concerns and issues are being articulated and negotiated under new technological and institutional circumstances. Traditional forms of one-to-one and one-to-many communication have been complemented by many-to-many communication, as typified by social network sites. All three of these prototypes of communication are now available and accessible on digital platforms that integrate a range of old and new media. A central aim of the project was to examine new digital and social media and old mass media as part of a complex and changing configuration of technologies, institutions, and users (Jensen \& Helles, 2015).

Previous research allowed us to isolate a cluster constituted by individuals with younger ages (aged between 14 and 30 years old), with a simultaneous use of networked media (i.e social network sites) and traditional media (Authors, 2015). We therefore decided to go further on the comprehension of this cluster and better perceive variables such as time spent on different media and devices, media usage in everyday life (namely in what refers to leisure time, or information search), the possible correlation between the type of activities conducted and the features of the media supporting those same activities. We specifically aimed to understand which medium was chosen to perform a specific activity and the daily options these individuals in particular took, namely in terms of managing their free time, deciding on which activities to conduct, or establishing a sense of the purpose of those same activities (social interaction, news consumption, leisure, or work). 


\section{Cross media activities and mediatisation}

The Internet and, to a certain extent, mobile technology, have enabled the establishment of a growing number of interconnections between media. Those bridges have been culturally appropriated by users and have shaped the way in which media participates within our lives (Jenkins, 2006; Livingstone, 1999). Additionally, the rise of digital and multimedia technologies enables the so-called old media to become more multifunctional, integrating functions such as information, communication, transaction, entertainment, sociability, education and identity building (van Dijk, 2006).

Arguing that the hypothesis of convergence often underlines discontinuities between the old and new and the erosion between media boundaries, some researchers propose the concept of intermediality, focusing in the "continuity of media forms" and in the "articulation and re-articulation of the media through changes in social and cultural contexts" (Herkman, 2012). Paying attention to the overall relationship between all available media types may allow to frame a more developed inquiry into how different media affect each other and why (Helles, 2013).

Plus, the complex and diverse nature of networked individualized digital media has led researchers to shift from technical determinism, focusing on the effects media have on individuals and society, to the relevance of communicative practices. More particularly, recent researches have explored the ways by which different flows of communication intersect across different categories of media and across the online/offline (Jensen and Helles, 2011; Jensen, 2013).

This performative crossing options between different media and the increasing role of media in daily life has changed what is nowadays called mediatized society. Mediatisation concerns the ubiquity and omnipresence of media in the current world (Hepp, 2013). Increasing mediatisation implies that different types of human actions are increasingly connected with the media (Kramp et al., 2014). Media are a relevant part of today's daily life, determinant for the evolution of civic cultures. "It may help to think of media not merely as technologies, but rather as means through which much of the life of society takes place" (Dahlgren \& Álvares, 2013, p. 51). In this context, cross media activities are a face of both contemporary societies and mediascape: media increasingly saturate everyday life and the so-called media diet is supplied by different platforms. This leads to cross-media practices (Bjur et al., 2014) that in turn have a direct and scarcely empirically studied relation with the organization of personal daily life and activities.

"In 20th-century discussions about the colonization of the lifeworld by the systemworld (and vice versa), the ongoing mediatisation of everyday life has gone barely noticed, to the extent that media are so pervasive and ubiquitous that they disappear. It is exactly the invisibility of media - their disappearance into natural user interfaces, the vanishing of concrete uses through convergence and portability, and their evaporation as the infrastructures of everyday interactions - that alerts us to their profound prominence." (Deuze, 2014, p. 207)

Since there is a construction of mediated lives through media options and since daily life choices are intrinsically related to media habits (Author 3, 2010; Jensen \& Helles, 2011; Jensen, 2013), everyday life media uses give us relevant sociological indicators of daily social and individual practices: they are not external or an adornment to our lives, instead they are part of it. Hepp (2013) refers to the opportunities 
of studying mediatised worlds in longitudinal studies but also in synchronous mediatisation research, especially with comparisons cross generations, pointing to possible different media habits and socializations. The author considers that research on mediatisation analyses the altering communicative figures of mediatised spheres (Hepp, 2013).

Although the use of "traditional" or "old media" such as television, newspapers or radio has not come to an end - as Henry Jenkins states, "history teaches us that old media never die" (Jenkins, 2001 p. 93) contemporary audiences have unprecedented degrees of freedom in selecting media for multiple purposes (Helles et al., 2015), particularly when considering the digital information sphere, which implies a opulent menu of options of interactive information (Bennett, 2007). Established media institutions and traditional business models are thus being challenged by digital options (Jensen \& Helles, 2015).

In this context, the so-called "old" or traditional media and "new" or networked media are deeply connected (Beckett, 2008) and tend to interact in many and new complex situations (Jenkins, 2006). This, in turn, transforms the fragmented and diverse mediated environments into spaces of multiple opportunities (Bennett, 2007; Beckett, 2008). For instance, the use of internet, especially for informational purposes is, at least in some European countries, very much connected to the use of traditional media, such as newspapers and books (Carlsson, 2010). However, this is a changing tendency, as stated Reuters Institute Digital News Report 2016 concerning news consumption.

"In terms of the key social networks for news, we have seen little significant change since last year with Facebook maintaining its dominant position. Across our sample $44 \%$ say they use Facebook for news, which in turn represents two-thirds of all Facebook users. YouTube is also a key network (19\%) while Twitter remains an important social network for news (10\%) favoured by journalists, politicians, and heavy news users in particular. Instagram continues to grow fast, along with WhatsApp in some countries" (Newman, Fletcher, Levy \& Nielsen, 2016, p. 10).

This growing tendency, nevertheless, also means that there still exists a complementarity between platforms, that is to say, different platforms still cohabit. Nielsen and Schrøder (2014) point precisely to a relative importance of social media for accessing, finding, and engaging with news. So we can identify and recognize the importance of online world, but also a lack of prominence comparing with traditional media.

The rise of new, digital media and the emergence of new patterns of media use may be interpreted as evidence of an "ecological reconfiguration", rather than a process of displacement (Gurevitch et al., 2009). Consequently, the mapping of changing patterns of media use has become more and more difficult to accomplish. Indeed, users combine and apply several media across diverse domains of their daily lives, as resources of social interaction in multiple and interrelated contexts of action (Helles et al., 2015). New information and communication technologies have thus radically changed norms and practices in several domains - from access to culture and politics to participation in private and public spheres - transforming the ways that people develop social ties, select cultural preferences or spend their time (Nimrod et al., 2015).

Digital technologies in general, and the network digital media such as the internet in particular, invite researchers to clarify the relationship between technology and practices: "one material medium may support several communicative practices; some communicative practices travel well between media; and 
certain familiar practices come back in style when new platforms become available" (Jensen, 2011, p. 13). It is the role of these material, productive and social features of the media in shaping patterns of media daily use that we are interested in.

Moreover, digital technologies have destabilized traditional roles of political communication and somewhat modified the communicative balance of power, as audiences are becoming more and more active participants in public communication. In fact, "digital convergence may lead to an intensification of public connection, as people become more skilful at adapting their media consumption to suit their everyday habits and pressures" (Couldry \& Markham, 2006, p. 256). These reconfigured social connections may have brought sociocultural advantages for some groups, who have now unprecedented opportunities to feel better informed (Gurevitch et al., 2009). In particular, young media audiences tend to be more innovative in the adoption of new media and communicative practices (Nimrod et al., 2015).

However, as Jenkins (2006) points out, convergence is a process and not an end in itself - citizens can be more powerful under a convergence culture, but mainly if they can recognize their power as participants in this new culture. Research tends to show that the more dynamics in youth social, cultural and economic capitals, the more there is a convergence and diverse use of media for different purposes and also for news consumption (Author 3, 2012, 2015).

In this convergence process, social class, gender and age are bases to better understand audiences and how they make sense of media, especially the Internet (Couldry et al., 2007; Maass \& Gonzalez, 2005). The economic situation of families and individuals has thus a great relevance in the mediatised choices, especially in a context of economic crises. Daily social routines, such as parents' habits (e.g. youngsters driven to school by parents), may have a role in youngsters options (e.g. consumption of news or music through the radio). Additionally, young adults show online news searching routines during weekdays, while at work (Author 3, 2010, 2012; Boczkowski, 2010; Jorge et al., 2011). This might imply that social structures also contribute to diverse mediatised options and to the way that media habits are appropriated.

Concerning the consumption of print media, newer types of media or Internet use, research has shown that traditional literacy in its different forms (namely intellectual skills developed through a lengthy period and constant exposure) are a function of the cultural capital acquired by individuals at an early age within the informal setting of the family (Nossek et al., 2015).

Overall, cross media consumption practices blur traditional frontiers between leisure and work time - for instance, when it transforms information acquisition practices into entertainment ones. At the same time, this calls for new forms of literacy and multitasking that resort to supplementation as a core media use feature.

\section{European "E-Audiences" and youngsters daily life use of media: aim, scope and methodology}

From an audience perspective, analysing the new media emergence and users' consumption of media provides an opportunity to take a deeper look at the ways by which the linkages between different media are culturally appropriated by users, shaping social patterns of interaction and cultural patterns of information exchange. Research indeed reveals that multitasking activities are a planned and conscious strategy according to the audience needs (Székely, 2015). In particular, younger segments of the population come out as early adopters of multitasking in media use (van Dijk, 2006) and new 
communicative practices, but more studies are needed of age groups as cohorts to establish the extent to which new technological resources and general life circumstances, respectively, shape communicative practices (Jensen \& Helles, 2011).

Looking at youngsters' daily media consumption activities, this article arises in the context of the work developed out of a European Cooperation in Science and Technology (COST) Action involving more than 300 scholars from 33 countries (http://www.cost-transforming-audiences.eu). The central aim of the "Eaudiences" developed within that COST action, was examining new and old media uses in the context of the changing configuration of technologies, institutions, and users (Jensen \& Helles, 2015), relying on a communication centric (rather than media centric) research design covering the full age range in an online survey applied to an extensive sample $(\mathrm{N}=10.742)$ from nine European countries (Belgium, Croatia, Denmark, Germany, Hungary, Israel, Italy, Poland and Portugal)i.

Aiming to produce a comprehensive account of audience preferences and practices across the full set of available media (Helles et al., 2015), the project intended to describe media usage patterns and thus examine the ways that people create their own individual media repertoires, representing a significant empirical step in regards to the interpretation of the shifting flows of communication between and across different media of diverse demographic and cultural segments (Hasebrink et al., 2015).

This comparative research employed national online samples designed to be representative of the population in each country for people aged 14 to 75 . Respondents were asked to answer questions regarding access to, use of, and time spent on different media and technological platforms; other questions addressed different kinds of Internet usage and the functions that respondents would use on their mobile phone; further questions included the private and public locations in which different media and genres are used as part of everyday life. Additionally, the analysis departed from a selection of prototypical social contexts of media use that included both concrete tasks and activities, from changing a dinner date to getting access to news.

An initial cluster analysis indicated a robust model with three clearly different clusters in this sample based on demographics and media usage (Authors, 2015): the first cluster was characterized by older ages, more likely to performing traditional media practices, but also more likely to write and read e-mails and to shop online; the second cluster was characterized by younger ages, more likely to use online media, social network sites, chat programs, download music and send SMS; finally, the third cluster was characterized by younger and medium ages (young adults and adults, aged between 14 and 30 years old) showing mixed media practices and strong online practices.

In this paper we will follow Hepp (2013) indications for using cohorts to explore different mediatisation's and ages groups. Departing from the results achieved within this cross-collaborative European project, this article focuses on those youngsters' daily use of media (identified on the third cluster), from adolescence to young adulthood, particularly in what refers to: time spent on different media and devices (e.g. to watch television on a TV set, computer or mobile phone; to listen to radio on a radio set, computer or mobile phone; to read newspapers, magazines and book in the printed version or on the internet or in the electronic version); and media usage in everyday life, in what respects leisure time, contact with an old acquaintance, or information research and confirmation.

In contemporary modern societies young people's transitions to adulthood (in general and particularly in labour context) have lost their linear nature. Compared to some decades ago when standard biographies were highly predictable and therefore provided both individual orientation and social integration, they may now be pictured as 'yo-yos' going up and down, back and forth (Pais, 1996). The age limit of child 
benefits, the conclusion of compulsory education or the voting age are key milestones that are mainly related to age, but adulthood is also considered as the time when young people become financially selfsufficient. The average age of independence increases especially combined with difficulties in getting a paid job and access to affordable housing have increased the length of the transition from youth to independence (Galland, 1997).

The first online generations are the Millennials (or Generation $Y$ ), the target respondents of this article (born early 1980's to mid 1990's to the early 2000's as last birth years), and the Z generation (that followed Millennials), referring only to a small part of the sample. This Millennials generation that grew up in an increasingly online and networked world is influenced by new technologies, especially social media. In fact, other characterizations, like "digital natives" (Prensky, 2001) or "net generation" (Tapscott, 1998), point to the idea of individuals that are online born and net navigators. Even so, their media uses are diverse and affected by different subgroups categories. According to Kilian, Hennigs and Langner (2012, p. 121), "the Restrained Millennials group is the easiest to serve because they are generally happy with traditional media products and services and only partly shift their time and income to the Internet". On the contrary, "Entertainment-seeking Millennials use social media more heavily but often in a leanback mode, where they merely consume the content that other users have created" (ibidem). Finally, "the Highly Connected Millennials are the role models of the Internet Generation. They adopt social media both passively and actively. They do not always use social media, but they do so quite often" (ibidem). Taking these previous ideas in consideration, this article aims to understand the role that different media play in the daily life of European youth: what do young people actually do when they are online and do they make sense of those activities (i.e do they see it as leisure or work time?), what amount of time do they spend in using specific media for information consumption purposes (or for social interaction purposes) and whether we are facing a replacement process of "old" media by new media.

Our core hypotheses are:

H1 - The supplementary use of "old" and "new" media by young audiences results in the blurring of the borders between leisure and work time;

$\mathrm{H} 2$ - Information use and consumption is an example of an activity performed by young audiences during their leisure time where supplementation is depicted;

$\mathrm{H} 3$ - Young audiences use networked individualized social media and social interaction features in order to manage their daily routines and overlap work and leisure activities.

Due to the vast extension of the survey, for the purpose of this article we selected the questions of the survey that were specifically related to the problems raised in the hypothesis mentioned above:

\section{1 - How much time did you spend on the following media? (Please think of yesterday);}

2- How much time did you spend on the following things? (Please think of yesterday - and any use you made of the internet yesterday);

3 - Imagine you have a few hours of free time to yourself. (You have the following options please indicate the three things that you are most likely to do); and

4 - Imagine that you and a friend are discussing an issue, and you need some factual information about that issue (e.g., a historical date or an economic figure) (To find out the information, you have the following options - indicate the three sources that you are most likely to use). 
Following the previously identified third cluster (14-30 years old respondents), the total sample examined in this article is constituted by 3609 individuals, divided by three young people age groups: 14-18 years old = 381 individuals; $19-24$ years old $=1580$ individuals; and $25-30$ years old $=1648$ individuals (see Table 1 - Distribution of the sample by country).

Table 1: Distribution of the sample by country

\begin{tabular}{|c|c|c|c|c|c|c|c|}
\hline & \multicolumn{7}{|c|}{ Age_Youth } \\
\hline & & \multicolumn{2}{|l|}{$14-18$} & \multicolumn{2}{|l|}{$19-24$} & \multicolumn{2}{|l|}{$25-30$} \\
\hline & & Count & Percentage \% & Count & Percentage \% & Count & Percentage \% \\
\hline \multirow{10}{*}{ Country } & BEL & 6 & $1,60 \%$ & 110 & $7,00 \%$ & 92 & $5,60 \%$ \\
\hline & CRO & 26 & $6,80 \%$ & 197 & $12,50 \%$ & 262 & $15,90 \%$ \\
\hline & $\mathrm{DE}$ & 79 & $20,70 \%$ & 125 & $7,90 \%$ & 164 & $10,00 \%$ \\
\hline & DK & 48 & $12,60 \%$ & 155 & $9,80 \%$ & 127 & $7,70 \%$ \\
\hline & HUN & 6 & $1,60 \%$ & 115 & $7,30 \%$ & 234 & $14,20 \%$ \\
\hline & ISR & 135 & $35,40 \%$ & 168 & $10,60 \%$ & 178 & $10,80 \%$ \\
\hline & IT & 8 & $2,10 \%$ & 206 & $13,00 \%$ & 172 & $10,40 \%$ \\
\hline & $\mathrm{PL}$ & 29 & $7,60 \%$ & 278 & $17,60 \%$ & 238 & $14,40 \%$ \\
\hline & PT & 44 & $11,50 \%$ & 226 & $14,30 \%$ & 181 & $11,00 \%$ \\
\hline & Total & 381 & $99,90 \%$ & 1580 & $100,00 \%$ & 1648 & $100,00 \%$ \\
\hline
\end{tabular}

The first age group corresponds to the younger audiences, associated with the children limit of age defined by the Convention on the Rights of the Child; this is also the age of transition from childhood to adulthood. The limit of age of the second group was defined by the boundary to youth age established by the General Assembly of United Nations; this is also an age where in Europe young people enter in the university or in the labour market. Finally, the third group corresponds to young adults. The EU policies aiming youth tend to end at the age of $29^{1}$, but there is no clear-cut definition of youth since it may be considered as a transition phase. Youth can be defined as a passage from childhood to adulthood and from a dependent to independent style of life, being therefore a moment of transition to a world of choice and risk (Walther et al., 2002). For the purposes of this study, individual answers per country were not considered.

\section{Data Analysis and results}

The data collected in the survey answered a battery of questions related with media usage in daily lives (for instance, time, place, media preferences), which made possible the exploration and testing our hypothesis, related with media uses of the youngsters, which are our focus in this paper. Data was analysed with the help of IBM SPSS Software (V22).

\footnotetext{
${ }^{1}$ The common survey dates coincided with relevant national events with significant media coverage in Portugal and in Italy, which could change the results.
} 
In terms of the overall sample of the E-audiences project, one of the most significant conclusions consisted in the fact that print media still constitute an important component of the new communications environment for European audiences: more than half of the population surveyed read print newspapers and nearly half still read print books; one-fifth of the sample read digital books. Results also suggested a general preference for traditional media use (watch TV in a TV set, listen to radio in a radio set, and read print books), which may indicate equivalence between the material conditions of a medium and its affordances and practices (Author 3, 2015). In all nine countries, "old" media still constitute an integral part of most users' media repertoires. Furthermore, online mobile media practices were much less common than either traditional or online media use via a computer, and were more likely to be performed by the youngest age group (14-30 years old).

In respect to youngsters' media consumption by device, it's clear that young people also spend a considerable amount of time consuming media contents in traditional media outlets (see Table 2): the highest means are in watching television in a traditional TV set (and the most impressive number is in the young adults group: 108 minutes). These results also show the importance of television in daily life, since all age groups said they had spent more than an hour watching television in the day before.

Table 2: Media consumption by device (yesterday/ minutes)

\begin{tabular}{|l|l|l|l|}
\hline \multirow{2}{*}{} & \multicolumn{3}{|c|}{ Age } \\
\cline { 2 - 4 } & $14-18$ & $19-24$ & $25-30$ \\
\cline { 2 - 4 } & Mean & Mean & Mean \\
\hline Watched television on a tv set & 82 & 94 & 108 \\
\hline Watched television on a mobile phone & 49 & 46 & 34 \\
\hline Listened to radio on a radio set & 21 & 10 & 4 \\
\hline Listened to radio on computer & 27 & 40 & 63 \\
\hline Listened to radio on mobile phone & 12 & 23 & 25 \\
\hline Read newspapers or magazines in the printed version & 8 & 8 & 6 \\
\hline Read newspapers or magazines on the internet & 12 & 13 & 12 \\
\hline Read books in the printed version & 15 & 23 & 27 \\
\hline Read books in the eletronic version & 19 & 31 & 24 \\
\hline Listened to audio books & 8 & 10 & 6 \\
\hline MP3 CD Wifi radio listening yesterday / Aggregated & 2 & 2 & 2 \\
\hline Video, DVD, TV box DVR watching yesterday / Aggregated & 75 & 89 & 79 \\
\hline Mobile messages - Number of text, image, sound massages by mobile \\
phone yesterday & 60 & 37 & 15 \\
\hline
\end{tabular}

Livingstone (2007) points out that the domestic media introduced into Western homes over the past half century or more are first conceived as communal but then, as they become cheaper and more portable, they are reconceived as personal media, particularly by children and young people. In sociological terms, this reflects an underlying process of individualisation, by which it is meant that traditional social distinctions (particularly social class) are declining in importance as determinants of people's (especially 
young people's) life course, resulting in a fragmentation of (or perhaps liberation from) traditional norms and values

That may lead us to the second most performed media consumption activity which shows a high time spent in watching television on a computer, specially between the 14-18 years old respondents. Younger media users who have had less contact with a specific media artefact in the past may resort to a material form they know, "provided it presents the necessary affordances to fulfil the gratifications they are looking for (watching a film)" (Authors, 2015, p. 409).

However, very few respondents said they used the mobile phone to watch television or listen to radio. This can be related with the internet services offered in each country at the time that the survey was conducted. A speedy connection to the Internet is needed in order to perform these activities on a mobile phone; if it is made through the mobile data, they consume a lot on of the data available per month. On the other hand, when they are made through wifi, it is frequent that the connection is not good enough. But it's very likely that this result will change in the future, with the fast technological developments and the better access to the internet all over. According to Special Eurobarometer 438, on E-Communications and the Digital Single Market, "mobile Internet access has increased significantly since the last survey up 23 points to $75 \%$ of households with mobile phone access. Overall, this means that in $69 \%$ of the EU households have at least one of its members with Internet access on their mobile" (European Commission, 2015 , p. 7). This means that there is effectively a lack of optimal conditions, in spite of the improvements. Regardless the device, the age group which listens to radio more time per diem is the oldest one (25-30 years old).

Listening to music on other formats as $\mathrm{CD}, \mathrm{MP3}$ or Wi-Fi is an activity in which respondents spend a great amount of time - more than an hour in all age groups, as well as watching other TV contents as DVDs or programs for TV Box DVR. One possible explanation for these results may be the stratification of audiences, i.e., they are actively seeking for what they want to listen or watch, even when they use traditional media outlets for the effect.

We can also say that the respondents spend more time reading newspapers and magazines on the internet and less on their print versions. But in what concerns reading books, all age groups prefer the printed version, the age group of 19-24 being the one that spends more time reading books. This can relate to the composition of the sample in what concerns to the referred age group: mostly constituted by students, possibly having more time to read than the people that have a full-time job, as it is most probable in the older age cohort of the sample.

We can, therefore, say that traditional devices (such as TV or radio sets, and books in the printed version) still matter a lot in terms of time spent on media by young audiences when compared to new platforms, except for the time spent on reading newspapers and magazines, in which the Internet version surpasses the printed version.

This also confirms the results of the sample of the study, which point out to a displacement process of print newspapers, with new technologies (digital news sites, convergence of these platforms with computers and smartphones) apparently fulfilling "both the traditional need for information and new and unique psychosocial needs for active social and political participation" (Nossek et al., 2015, p. 379).

These results consubstantiate what we already suspected: sending text messages is mainly a teenager's habit. The number of minutes spent texting not only decreases when ages grow, but the difference of time spent between the youngest age group and the second one is almost the double. Finally, we can tell that listening to audio books is the less popular activity amongst the ones listed in the survey. 
Table 3: Internet activities (yesterday)

\begin{tabular}{|c|c|c|c|}
\hline & \multicolumn{3}{|l|}{ Age } \\
\hline & $14-18$ & $19-24$ & $25-30$ \\
\hline & Mean & Mean & Mean \\
\hline Getting news / Aggregated & 12 & 21 & 24 \\
\hline Writing and reading e-mails / Aggregated & 10 & 22 & 32 \\
\hline Playing computer games online / Aggregated & 23 & 22 & 21 \\
\hline Using social network sites / Aggregated & 79 & 68 & 48 \\
\hline Using chat programs / Aggregated & 25 & 17 & 13 \\
\hline Reading entries at debate sites, blogs / Aggregated & 13 & 11 & 10 \\
\hline Writing entries at debate sites, blogs / Aggregated & 8 & 4 & 3 \\
\hline Online shopping, banking, travel reservation etc. / Aggregated & 4 & 6 & 7 \\
\hline $\begin{array}{l}\text { Using websites concerning my interests or hobbies / } \\
\text { Aggregated }\end{array}$ & 25 & 26 & 23 \\
\hline Other please specify & 5 & 6 & 6 \\
\hline
\end{tabular}

In respect to Internet usage (see Table 3), we can conclude that "using social network sites" is the activity in which the youngsters, in general, spend more time, confirming SNS's relevance in the current web landscape. The age group 14-18 said they had spent, in average, 79 minutes in SNS in the previous day of the survey.

One of the explanations to these results can be the "need for popularity", which assumes a major importance in the teenage years. Indeed, previous research shows that this need is the strongest and most consistent predictor of SNS behaviours (Utz et al., 2012), as the use of SNS has effects in teenager's self-esteem and well-being (Valkenburg et al., 2006).

The second most popular activity for all age groups is "using websites concerning my interests and hobbies". All of the three age groups spend similar time doing that, which makes us think that the Internet websites are a major source of information to the so-called Millennials. It shows that they generally trust in the information they discover online and is where they can find relevant information related to their interests and hobbies, probably because of the enormous amount of information about everything available onlineii.

Major trends were found between age groups in the following cases: while the youngsters spend 25 minutes in average using chat programs, the oldest (25-30 years old) don't spend much time in this activity, spending more time writing and reading e-mails (which could be related to their profession) as well getting news. The youngest group is the one spending less time writing and reading e-mails and news. This figure confirms our hypothesis that networked digital media is being more used mostly for entertainment purposes in this cohort.

In respect to the global sample of the project, one of the conclusions pointed out to a significant age divide in terms of media practices, "with the younger audience manifesting greater use of social media and messengers and the older audience displaying use of traditional synchronous mass media and older forms of new media, such as e-mail" (Nimrod et al., 2015, p. 330).

When we surveyed the ways that the respondents used to contact an old acquaintance (they could choose 
three options of a pre-given range), the most chosen was through a social network site and the less chosen was by posting a letter. The second option more chosen was through a SMS, followed by a phone call in third. The results are homogeneous, i.e., they don't show a great variation between age groups, which make us believe that the preferences of teenagers and young adults are similar.

Concerning this issue, digital technologies in general, and the Internet in particular (integrating one-toone, one-to-many, and many-to-many forms of communication), indeed invite research that seeks to clarify the relationship between media and communicative practices via the understanding of the role individual and collective communicative needs have in shaping those same communicative practices through the use of different platforms as a mean to perform distinctive activities (Jensen, 2011). In fact, the arrival of new media may change the usefulness of the existing ones - Rasmus Helles (2013) gives the example of Denmark and other Western countries, in which the decline in text messaging is due to social networking services (SNSs) becoming available on mobile media, "enabling young people to shift portions of their group communication from cluttered flows of multirecipient text messages to a more streamlined format on Facebook" (Helles, 2013, p. 16).

To better understand the role played by different media in their daily life, we asked the respondents to imagine that they had free time on a Saturday afternoon and what would they do according to a range of pre-given options (see Table 4).

Table 4: Free time

\begin{tabular}{|c|c|c|c|c|c|c|c|}
\hline & & \multicolumn{6}{|c|}{ Age_Youth } \\
\hline & & \multicolumn{2}{|l|}{ 14-18 } & \multicolumn{2}{|l|}{$19-24$} & \multicolumn{2}{|l|}{$25-30$} \\
\hline & & Count & Column N \% & Count & Column N \% & Count & ColumnN \% \\
\hline \multirow{2}{*}{$\begin{array}{l}\text { Send SMS to friends } \\
\text { or family }\end{array}$} & No & 275 & $72,2 \%$ & 1178 & $74,6 \%$ & 1374 & $83,4 \%$ \\
\hline & Yes & 106 & $27,8 \%$ & 402 & $25,4 \%$ & 274 & $16,6 \%$ \\
\hline \multirow{2}{*}{$\begin{array}{l}\text { Call friends or } \\
\text { family on the phone }\end{array}$} & No & 287 & $75,3 \%$ & 1200 & $75,9 \%$ & 1167 & $70,8 \%$ \\
\hline & Yes & 94 & $24,7 \%$ & 380 & $24,1 \%$ & 481 & $29,2 \%$ \\
\hline \multirow{2}{*}{$\begin{array}{l}\text { Chat online with } \\
\text { friends or family }\end{array}$} & No & 339 & $89,0 \%$ & 1398 & $88,5 \%$ & 1497 & $90,8 \%$ \\
\hline & Yes & 42 & $11,0 \%$ & 182 & $11,5 \%$ & 151 & $9,2 \%$ \\
\hline \multirow{2}{*}{$\begin{array}{l}\text { Write emails to } \\
\text { friends or family }\end{array}$} & No & 356 & $93,4 \%$ & 1506 & $95,3 \%$ & 1533 & $93,0 \%$ \\
\hline & Yes & 25 & $6,6 \%$ & 74 & $4,7 \%$ & 115 & $7,0 \%$ \\
\hline \multirow{2}{*}{$\begin{array}{l}\text { Visit friends of } \\
\text { family }\end{array}$} & No & 280 & $73,5 \%$ & 1114 & $70,5 \%$ & 1084 & $65,8 \%$ \\
\hline & Yes & 101 & $26,5 \%$ & 466 & $29,5 \%$ & 564 & $34,2 \%$ \\
\hline \multirow{2}{*}{$\begin{array}{l}\text { Use social network } \\
\text { sites }\end{array}$} & No & 203 & $53,3 \%$ & 875 & $55,4 \%$ & 1017 & $61,7 \%$ \\
\hline & Yes & 178 & $46,7 \%$ & 705 & $44,6 \%$ & 631 & $38,3 \%$ \\
\hline \multirow{2}{*}{$\begin{array}{l}\text { Read printed books, } \\
\text { newspapers or } \\
\text { Magazines }\end{array}$} & No & 282 & $74,0 \%$ & 1154 & $73,0 \%$ & 1170 & $71,0 \%$ \\
\hline & Yes & 99 & $26,0 \%$ & 426 & $27,0 \%$ & 478 & $29,0 \%$ \\
\hline \multirow{2}{*}{ Visit websites } & No & 268 & $70,3 \%$ & 1013 & $64,1 \%$ & 968 & $58,7 \%$ \\
\hline & Yes & 113 & $29,7 \%$ & 567 & $35,9 \%$ & 680 & $41,3 \%$ \\
\hline \multirow{2}{*}{ Watch video or DVD } & No & 325 & $85,3 \%$ & 1332 & $84,3 \%$ & 1438 & $87,3 \%$ \\
\hline & Yes & 56 & $14,7 \%$ & 248 & $15,7 \%$ & 210 & $12,7 \%$ \\
\hline
\end{tabular}




\begin{tabular}{|l|l|l|l|l|l|l|l|}
\hline $\begin{array}{l}\text { Listen to music on } \\
\text { CD, MP3, or similar }\end{array}$ & No & 304 & $79,8 \%$ & 1321 & $83,6 \%$ & 1468 & $89,1 \%$ \\
\cline { 2 - 8 } & Yes & 77 & $20,2 \%$ & 259 & $16,4 \%$ & 180 & $10,9 \%$ \\
\hline \multirow{2}{*}{ Listen to radio } & No & 342 & $89,8 \%$ & 1461 & $92,5 \%$ & 1502 & $91,1 \%$ \\
\cline { 2 - 8 } & Yes & 39 & $10,2 \%$ & 119 & $7,5 \%$ & 146 & $8,9 \%$ \\
\hline \multirow{2}{*}{ Watch TV } & No & 237 & $62,2 \%$ & 1032 & $65,3 \%$ & 1013 & $61,5 \%$ \\
\cline { 2 - 8 } & Yes & 144 & $37,8 \%$ & 548 & $34,7 \%$ & 635 & $38,5 \%$ \\
\hline \multirow{2}{*}{ Other media use } & No & 369 & $96,9 \%$ & 1513 & $95,8 \%$ & 1569 & $95,2 \%$ \\
\cline { 2 - 8 } & Yes & 12 & $3,1 \%$ & 67 & $4,2 \%$ & 79 & $4,8 \%$ \\
\hline
\end{tabular}

The results show that Internet is an important medium to spend free time, perhaps the most important one, at least in the age groups considered in the sample for this article. The preferred activity for a Saturday afternoon is using social network sites. At the same time, watching TV is still a very mentioned activity to fulfil youngsters' leisure time, being the second one most chosen.

Visiting websites is the third most chosen Internet activity. To call friends or family is also a common activity, as well as sending SMS, but, surprisingly, almost as common as it is read printed books, newspapers or magazines.

We also asked the respondents to imagine a scenario where they want to find some information quickly, such as the result of an election or who won a football match. They also could choose three options, and the most chosen one was check the information in websites. It was followed by the use a social network site (especially by the youngest group, 14-18) and turning on TV or radio. The less probable way mentioned was a chat program (see Table 5).

Table 5: How to check factual information

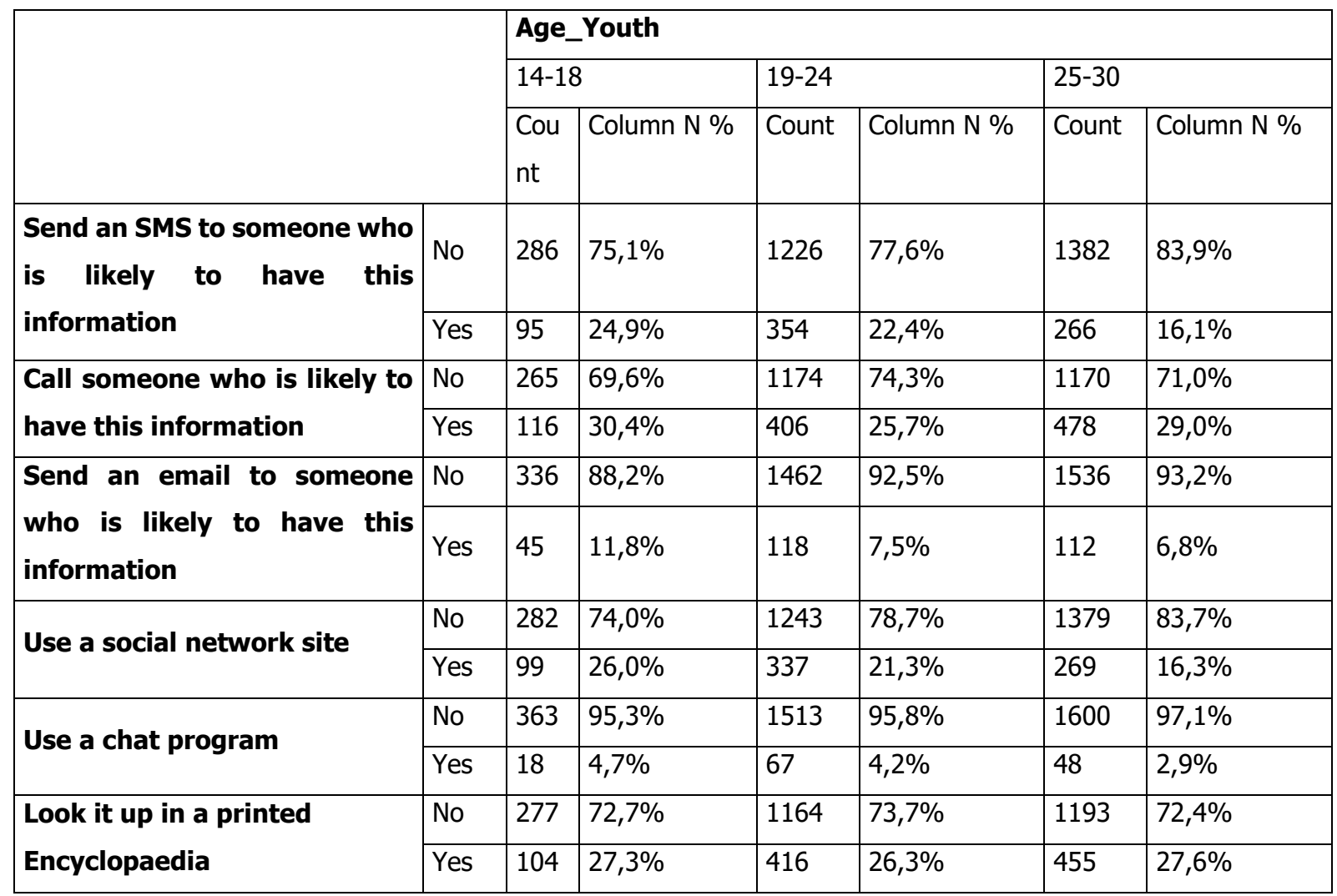




\begin{tabular}{|l|l|l|l|l|l|l|l|}
\hline \multirow{2}{*}{$\begin{array}{l}\text { Look it up via Google or other } \\
\text { search engines }\end{array}$} & No & 93 & $24,4 \%$ & 331 & $20,9 \%$ & 271 & $16,4 \%$ \\
\cline { 2 - 8 } & Yes & 288 & $75,6 \%$ & 1249 & $79,1 \%$ & 1377 & $83,6 \%$ \\
\hline \multirow{2}{*}{$\begin{array}{l}\text { Look it up in at a specific } \\
\text { website }\end{array}$} & No & 146 & $38,3 \%$ & 604 & $38,2 \%$ & 594 & $36,0 \%$ \\
\cline { 2 - 8 } & Yes & 235 & $61,7 \%$ & 976 & $61,8 \%$ & 1054 & $64,0 \%$ \\
\hline \multirow{2}{*}{$\begin{array}{l}\text { Other } \\
\text { No }\end{array}$} & 381 & $100,0 \%$ & 1574 & $99,6 \%$ & 1643 & $99,7 \%$ \\
\cline { 2 - 8 } & Yes & 0 & $0,0 \%$ & 6 & $0,4 \%$ & 5 & $0,3 \%$ \\
\hline
\end{tabular}

Another scenario presented to the respondents was: imagine you have a friend at your home and you have doubts about some fact. How would you confirm the information? As in other questions, respondents could choose three options.

Confirming our expectations, to search for the information on Google or another search engine was the option with more answers by far. The second choice was also to look for the information online, but this time in specific websites. It seems that "Internet really knows it all" for our respondents. If they choose to ask to another person, the most likely way of doing it is calling, instead of sending a text message or e-mail.

To change a dinner invitation, the preferred form is through an SMS or a phone call. We believe that happens because of the urgency of delivering the message to the recipient. In this one, the Internet is not prevalent, probably because you still don't know if everyone is always connected. As expected, the less likely way to change a dinner invitation is by posting a letter.

\section{Discussion and Final Remarks}

In our research we found that Internet is ubiquitous in youngsters daily lives, not only for the enactment of daily life activities (as checking for information and other leisure activities) but also for social purposes. Nevertheless, data also shows that there is a complementarity in media usage amongst this group, with television still being very relevant as a device in which they spent a considerable amount of time. There are no big differences among these age groups, but even so we will point to some of the major differences we identified.

Specifically regarding media consumption by device (yesterday/minutes), we found out that youngsters' spend considerable time with traditional media, mainly watching television in a traditional set. However, young people between 14-18 revelled to spend a lot of time watching television on a computer. This choice could be related with the bedroom culture that Sonia Livingstone (2007, p. 7) points out: "Personal ownership of media dramatically increases in the early teenage years, part and parcel of the development of identity."

The option of watch television in a computer could also express a desire for a more individualized consumption of contents, in their own device (the computer is more often of their than tv devices, which are more frequently shared by the all family members). They have more privacy to choose what to watch. Data also shows that respondents spend more time reading online newspapers and magazines than reading print versions. In this regard, we must not forget that this was an online survey, representative for that regard, with people that are online. Nielsen and Schrøder (2014) and Newman, Fletcher, Levy and Nielsen (2016) also pointed to an evolution with complementarities, thus supporting our 
supplementary hypothesis.

Looking specifically at networked digital media (i.e the internet), using social networks is the most frequent activity carried online, especially amongst the younger group, that in average spent 79 minutes using SNS in the day prior to the of the survey. Particularly looking at the use of free time, results point to the major relevance that internet has amongst all age groups. This might be easily connected with the use of SNS, but, once again, TV is also pointed as relevant in leisure activities. In what concerns checking for factual information, search for information on Google or another search engine was the option with more answers. The second choice was also to look for the information online through specific websites. Going back to our initial hypotheses, we can now point to some of the results:

H1 - The supplementary use of "old" and "new" media by young audiences results in the blurring of the borders between leisure and work time: this hypothesis is confirmed. Examples of such are the use of the internet for information (news) consumption, and the simultaneous use of TV and SNS.

$\mathrm{H} 2$ - Information use and consumption is an example of an activity performed by young audiences during their leisure time where supplementation is depicted: this hypothesis is confirmed. Data also shows that young audiences resort more than other age groups to networked individualized media to perform leisure related activities like entertainment and information consumption. However, this is far from being a substitution process, namely in what concerns television and online newspapers.

H3 - Young audiences use networked individualized social media and social interaction features in order to manage their daily routines and overlap work and leisure activities: this hypothesis is confirmed. The adoption and appropriation processes young audiences follow enact activities that resort to these "new" media material and social features as a mean to blur the frontiers between leisure and work time. Both the drivers and the consequences of these processes have not been studied in the present context, but more research on this topic is clearly needed.

As a final remark, we would like to note that "complementarity" along with supplementation are the two main patterns of youngsters' daily use of the media. Both these processes should be taken into consideration when it comes to define and promote public policies in the area of youth, namely in face of an ever more mediatised and information populated social context.

Additionally, we must underline that this article results of the analysis of an online sample, meaning that these respondents all use, at least to at a certain degree, the internet. Results identify changes in daily life use of digital devices, which may point to the need of continuously promote digital affordances, from access to use. A different sample - i.e not only made of "online" subjects may have pointed to lower digital access and use. We are aware of the limitations of a study entirely based on quantitative comparative surveys, and future research on youngsters use of digital media, should include both exploratory qualitative methods, namely netnography, and descriptive structured and unstructured observation, namely based on data for online behaviours. The use of qualitative methods in the context of exploratory and descriptive designs, not only would allow us to gain a better insight of the uses youngsters do of digital media while conducting their during daily life activities, but would also allow us to better understand the representativeness of such uses and infer on possible future avenues of 
development. Still on the topic of future research, we would also like to point out that these results also highlight the need to conduct the same type of research with different types of samples and further cross data between different countries.

\section{References}

Beckett, C. (2008). SuperMedia: Saving Journalism so it can Save the World. West Sussex: Blackwell Publishing.

Bennett, W. L. (2007). Civic Learning in Changing Democracies: Challenges for Citizenship and Civic Education. In P. Dahlgren (ed) Young Citizens and New Media: Learning for Democratic Participation (pp. 60-77). New York: Routledge.

Bjur, J., Schroeder, K., Hasebrink, U., Coutrois, C., Adoni, H., \& Nossek, H. (2014). Cross-media use. Unfolding complexities in contemporary audiencehood. In N. Carpentier, K. C. Schroeder and L. Hallett (eds), Audience transformations. Shifting audience positions in late modernity (pp. 1529). New York and London: Routledge.

Boczkowski, P. J. (2010). News at Work: Imitation in an Age of Information Abundance. Chicago: The University of Chicago Press.

Brites, M.J. (2010). Jovens (15-18 anos) e informação noticiosa: a importância dos capitais cultural e tecnológico. Estudos em Comunicação/Communication Studies, 8: 169-192. ISSN: 1646-4974. URL: http://www.ec.ubi.pt/ec/08/pdf/EC08-2010Dez.pdf

Brites, M.J. (2012). Jovens e informação política: a televisão ainda é importante? In R. Figueiras (Ed.), Esmiuçando os Sufrágios. As Eleições Europeias, Legislativas e Autárquicas de 2009 (pp. 253276). Lisboa: Colecção Estudos de Comunicação, Universidade Católica Editora. ISBN: 978-97254-0343-3

Brites, M.J. (2015). Jovens e culturas cívicas: Por entre formas de consumo noticioso e de participação. Covilhã: Livros LabCom. ISBN: 978-989-654-199-6. doi:10.13140/2.1.2141.0081. URL: http://www.livroslabcom.ubi.pt/book/128

Carlsson, U. (2010). Children and Youth in the Digital Media Culture: Global and Nordic Perspectives. In U. Carlson (edt.), Children and Youth in the Digital Media Culture (pp. 9-24). Goteborg: Nordicom.

Couldry, N., Livingstone, S., \& Markham, T. (2007). Media Consumption and Public Engagement: Beyond the Presumption of Attention. London: Palgrave Macmillan.

Couldry, N., \& Markham, T. (2006). Public Connection through Media Consumption: Between Oversocialization and De-Socialization?. The Annals of American Academy of Political and Social Science 608(1): 251-269.

Damásio, M., Henriques, S., Silva, M. T., Pacheco, L., \& Brites, M. J. (2015). Between Old Broadcast Media and New Networked Media: Materiality and Media Consumption Practices. International Journal of Communication, 9: 386 - 411.

Dahlgren, P., \& Álvares, C. (2013). Political participation in an age of mediatisation towards a new research agenda. Javnost: The Public, 20(2): 47-66.

Deuze, M. (2014). Media Life and the Mediatization of the Lifeworld. In Andreas Hepp and Friedrich Krotz (Edts.), In Mediatized Worlds: Culture and Society in a Media Age (pp. 207-220). London: 
Palgrave Macmillan.

European Commission (2016). Special Eurobarometer 438: E-Communications and the Digital Single Market. Retrieved from European Union: http://www.eena.org/download.asp?item_id=177; 1st of October 2016.

Gurevitch, M., Coleman, S., \& Blumler, J. G. (2009). Political Communication - old and new mediarelationships. The Annals of the American Academy of Political and Social Science, 625: 164-181.

Galland, O. (1997). Sociologie de la jeunesse. Paris: Armand Colin.

Giddens, A. (1984). The constitution of society. Berkeley, CA: University of California Press.

Hallin, D. C., \& Mancini, P. (2004). Comparing media systems: Three models of media and politics. Cambridge, UK: Cambridge University Press.

Hasebrink, U., Jensen, K. B., Bulck, H. V. D., Holig, S., \& Maeseele, P. (2015). Changing patterns of media use across cultures: a challenge for longitudinal research. International Journal of Communication, 9: 435-457.

Helles, R. (2013). Mobile communication and intermediality. Mobile Media \& Communication, 1(1): 1419.

Helles, R., Ormen, J., Radil, C., \& Jensen, K. B. (2015). The Media landscapes of European audiences. International Journal of Communication, 9: 299-320.

Herkman, J. (2012). Introduction: intermediality as a theory and methodology. In J. Herkman, T. Hujanen \& P. Oinonen (eds). Intermediality and media change (pp. 10-27). Tampere: Tampere University Press.

Hepp, A. (2013). The communicative figurations of mediatized worlds: Mediatization research in times of the 'mediation of everything". European Journal of Communication, 28 (6): 615-629.

Jenkins, H. (2006). Convergence Culture: Where Old and New media Collide. New York and London: New York University Press.

Jenkins, H. (2001). 'Convergence? I Diverge'. Technology Review. Retrieved from http://phase1.nccrtrade.org/images/stories/jenkins_convergence_optional.pdf

Jensen, K. B. (2013) How to do things with data: Meta-data, meta-media, and meta-communication. First Monday, 18(10). Retrieved from http://firstmonday.org/ojs/index.php/fm/article/view/4870/3751

Jensen, K. B. (2011). Meta-media and meta-communication: Revisiting the concept of genre in the digital media environment. MedieKultur, 51, 8-21.

Jensen, K. B., \& Helles, R. (2015). Audiences across media. A comparative agenda for future research on media audiences. International Journal of Communication, 9: 291-298.

Jensen, K. B., \& Helles, R. (2011). The internet as a cultural forum: implications for research. New Media \& Society, 13(4): 517-533.

Jorge, A., Brites, M. J., \& Francisco, K. (2011). Contactar, entreter, informar: Um retrato da inclusão digital de jovens e seus familiares em Portugal. Observatório (OBS*), 5(3): 101-131.

Kilian, T., Hennigs, N., \& Langner, S. (2012). Do Millennials read books or blogs? Introducing a media usage typology of the internet generation. Journal of Consumer Marketing, Vol. 29(2), 114 124. Permanent link to this document: http://dx.doi.org/10.1108/07363761211206366

Kramp, L., Carpentier, N., \& Hepp, A. (2014). Introduction: Investigating the Everyday Presence of Media. In N. C. L. Kramp, A. Hepp, I. Tomanić Trivundža, H. Nieminen, R. Kunelius, T. Olsson, E. Sundin, 
\& Ri. Kilborn. (Ed.), Media Practice and Everyday Agency in Europe (pp. 9-22). Bremen: edition lumière.

Livingstone, S. (1999). New Media, New Audiences? (online). London: LSE Research Online.

Livingstone, S. (2007). From family television to bedroom culture: Young people's media at home. In E. Devereux (Ed.), Media Studies: Key issues and Debates (pp. 302-321). London: Sage.

Maass, M., \& Gonzalez, J. A. (2005). Technology, global flows and local memories: Media generations in global Mexico. Global Media and Communication 1: 105-122.

Newcomb, H \& Hirsch, P (1983). Television as a Cultural Forum: Implications for Research. Quarterly Review of Film and Video 8(3):45-55.

Newman, N., Fletcher, R., Levy, D. A. L., \& Nielsen, R. K. (2016). Reuters Institute Digital News Report2016. Retrieved from Reuters Institute for the Study of Journalism, 16th October 2016. http://www.digitalnewsreport.org

Nielsen, R. K. \& Schrøder, K. C. (2014). The Relative Importance of Social Media for Accessing, Finding, and Engaging with News. Digital Journalism, 2:4, 472-489, DOI: $10.1080 / 21670811.2013 .872420$

Nossek, H., Adoni, H., and Nimrod, G. (2015). Is print really dying? The state of print media use in Europe. International Journal of Communication, 9: 365-385.

Pais, J. M. (1996). A geração yô-yô, Dinâmicas Multiculturais, Novas Faces, Outros Olhares. Actas das sessões temáticas do II Congresso Luso-Afro-Brasileiro de Ciências Sociais. Lisboa: ICS, pp. 111125.

Prensky, M. (2001). Digital Natives, Digital Immigrants Part 1. On the Horizon, 9, 2001, pp. 1-6.

Székely, L. (2015). The typology of multitasking activity. European Journal of Communication, 30(2): 209225.

Tapscott, D. (1998). Growing up digital: the rise of the net generation. McGraw-Hill, New York.

UNESCO (2013). Manual to accompany the International Standard Classification of Education 2011, UNESCO Institute for Statistics. DOI http://dx.doi.org/10.15220/978-92-9189-150-4-en

Utz, S., Tanis, M., \& Ivar V. (2012). It Is All About Being Popular: The Effects of Need for Popularity on Social Network Site Use. Cyberpsychology, Behavior, and Social Networking, 15(1): 37-42.

Walther, A., Hejl, G. M. \& Jensen T. B. (2002). Youth Transitions, Youth Policy and Participation. State of the Art Report. Research Project YOYO. http://www.irisegris.de/yoyo/pdf/YoyoWP1StateofArt.pdf

Valkenburg, P. M., Peter, J., \& Schouten, A. P. (2006). Friend Networking Sites and Their Relationship to Adolescents' Well-Being and Social Self-Esteem. CyberPsychology \& Behavior, 9(5): 584-590.

van Dijk, J. A.G.M. (2006). The Network Society, Social Aspects of New Media. London: Sage Publications. 